Okajimas Fol. anat. jap., $48: 333-345,1971$

\title{
Comparative Morphology of the Mammalian Mandible in Relation to Food Habit
}

\author{
By \\ Hiroshi Hoshi \\ Department of Anatomy, Faculty of Medicine, University of Tokyo \\ -Received for publication, June 23, 1971-

\section{Introduction}

It is beyond dispute that the shape and structure of the mammalian mandible are influenced and controlled by the masticatory activities. Many developmental and experimental studies of the mandible have clarified the relation between structure and function. But the macroscopic observation from this point of view is not available. Most of the well-known textbooks of comparative and veterinary anatomy are not concerned with this problem, except one by Weber who noted remarks about the angular process and the height of the condyloid process. There are several papers describing different features of the mammalian mandible (Toldt, Peteff, Kühlhorn, Lebedinsky, Häberle, Bechet) and some of these will be referred to in the following chapter.

The present paper deals with the results of macroscopic observations on mandibles of mammals with special reference to the relationship between the shape of the mandible and the food habit. Although there are a lot of morphological items to be discussed about the mandible, the present study is focused on analysis of the figure of Norma lateralis, since this approach is most valuable to examine the relationship under consideration.

\section{Materials and Method}

Materials comprised 80 skulls of 78 mammalian species. They partly belonged to the Department of Anatomy, University of Tokyo, and partly to the National Science Museum in Tokyo. Every mandible was photographed in the lateral view. Enlargement was done in such a way that every pictured mandible had same length on the photographic paper irrespective of the real size. To represent the relative length of the condyloid process, $i . \theta$. relative height of the 
condyle (caput mandibulae), the "condyle height index" was proposed as shown in Fig. 1.

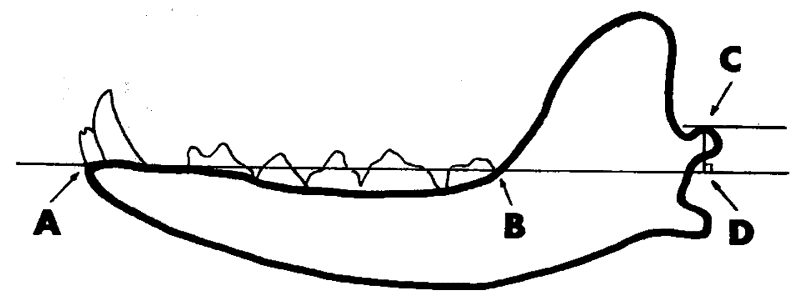

Fig. 1. The condyle height index $=\frac{C D}{A D} \times 100 . A:$ the alveolar border of the mesial incisor. $B$ : the alveolar border of the last molar. $C$; the top of the condyloid process. $\mathrm{D}:$ the foot of the perpendicular. The line drawn through the points A and B represents the “Alveolarrand-Linie" by Martin's method (1957).

\section{Findings}

The Mandible of Carnivora and Ungulata (21 fissipedes, 3 pinnipedes, 13 artiodactyls, 3 perissodactyls). There is a great resemblance in shape among mandibles of carnivores as well as among those of ungulates, despite the variety in other skull features.

(1) The corpus mandibulae. The mandibular body of the carnivores shows a slight upward concaveness in its lateral view. It is evenly massive from the canine to the molar region, and the whole shape may be compared to a canoe. On the contrary, the ungulates have a tall mandibular body, which is massive at the mandibular angle, and its height decreases gradually toward the symphyseal portion. Among ungulates, the body is tallest and most massive in non-ruminants; that of perissodactyls comes next, and that of ruminants is most slender. The alveolar border shows an upward concaveness in the last two, but in non-ruminants (omnivorous forms) it is straight or convex.

(2) The coronoid process. In carnivores, this process is strikingly large, massive, and triangular in lateral view, and its upper part is to some degree slant posteriorly in many forms. These are the characteristics of the mandible of carnivores. In ungulates, the process is by far smaller than in carnivores. The ruminants have a long and slender process, which is placed deep in the temporal fossa and is strongly curved posteriorly. In non-ruminants and perissodactyls, the process is short and not so curved as in ruminants.

(3) The masseteric fossa. In carnivores, there is a large and deep fossa spreading over the entire lateral surface of the coronoid process. It is deepest at the antero-inferior corner, but posteriorly 
the demarcation is often obscure. In some species (bear, etc.), it is divided into upper and lower parts by a low crest. In ungulates, the lateral surface of the ramus is broad and rough, and the fossa is found as a small depression limited to the upper half of the ramus. The fossa is clearly seen in non-ruminants and perissodactyls, but more or less obscure in ruminants.

(4) The angular process. There is a short stick-like process protruding posteriorly at the mandibular angle. This is found in carnivores, but absent in ungulates. Weber's description that this process appears in "many" carnivores implies the possibility of its lacking. However, as far as the present materials are concerned, no species of fissipede carnivores lacks this process, although in pinnipedes (aquatic carnivores) the process is nothing but a tubercle.

(5) The condyloid process. The difference in the height of the process is worth noticing. The condyloid process is relatively short in carnivores and tall in ungulates. Mean values of the condyle height index are $7.7(0.95-18.2)$ in carnivores and $25.6(16.0-39.4)$ in ungulates. Note a considerable difference between carnivores and ungulates. Panda (Ailurus fulgens) represents an exceptional case. The index of the animal is 28.0, which is within the range of ungulates. This may be caused by its complete herbivorous alimetation: Panda takes no animal food, but only bamboo sprouts or leaves. It is interesting, however, that other parts of the mandible are shaped in the same way as in other carnivores.

Surely, there are "omnivorous" forms among carnivores: bear, racoon, coati, badger, racoon dog, fox, etc., but their mandibular characters coincide with those of carnivorous forms.

The Mandible of Insectivora and Chiroptera (2 shrews, one mole, 2 hedgehogs, 2 flying foxes, 2 bats). The mandible of Insectivora and Chiroptera has features similar to those of the carnivores, apart from such minute differences that (a) the mandibular body of the insectivores is more slender than others, (b) the mandible of Chiroptera has no upward concaveness. The coronoid process is large and triangular; the masseteric fossa is well-developed though shallower than in carnivores; the angular process is present in insectivores and bats, while it is absent in flying foxes. Weber ascribes the shortness of the condyloid process to all these species. But the condyle height index is 20.9 in mole, 27.2 and 30.6 in hedgehogs, 22.8 and 19.4 in shrews, all being inside the range of ungulates, while it is 11.5 and 13.4 in flying foxes and 7.8 and 16.2 in bats, all being inside the range of carnivores. After all, many features of the mandible of insectivores and Chiroptera coincide with those of carnivores, except the tall condyloid process in the insectivores. 

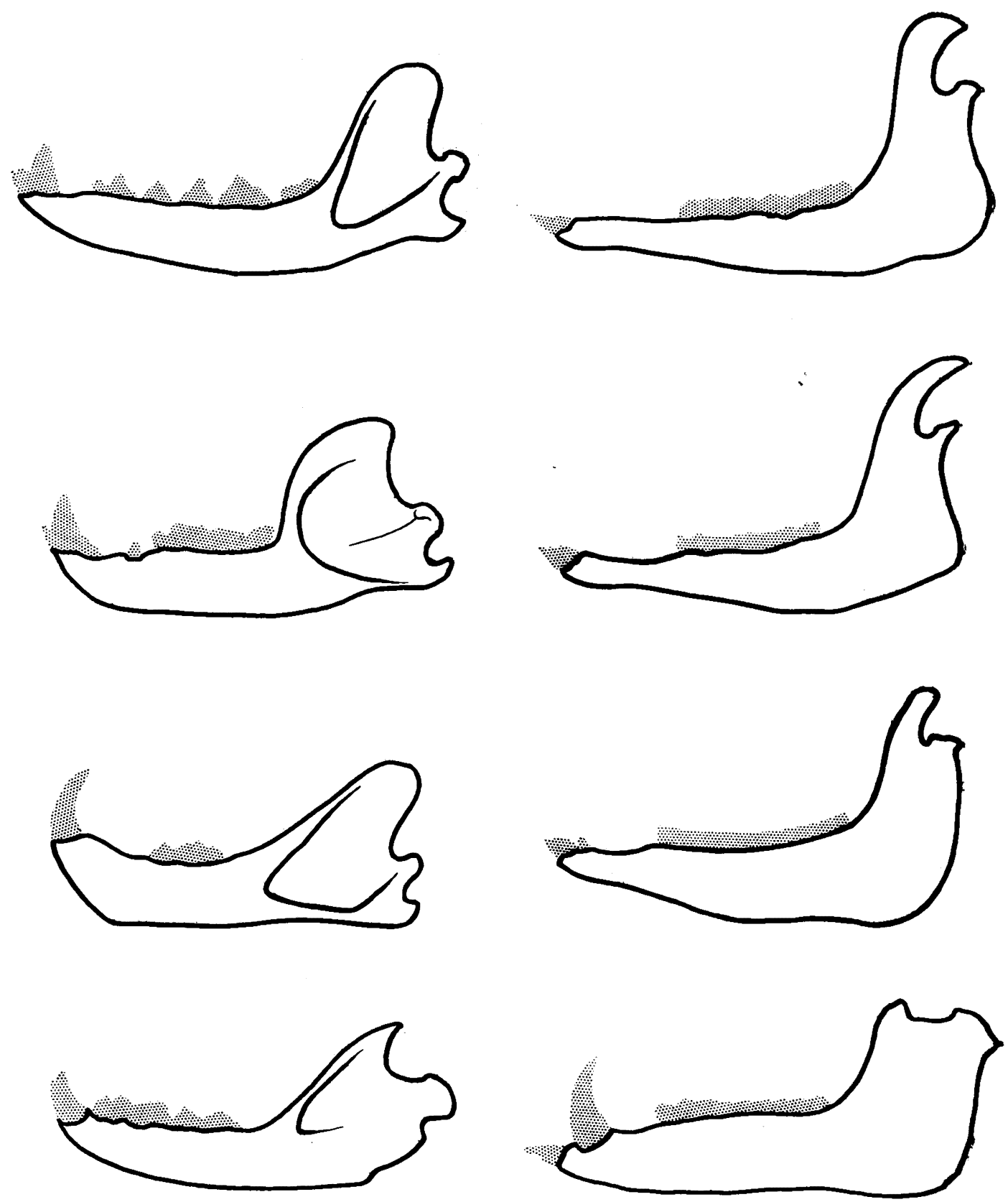

Fig. 2. Mammalian mandibles in Norma lateralis. Left: (top to bottom) dog, brown bear, tiger, common seal. Right: Japanese serow, sheep, horse, wild pig. 

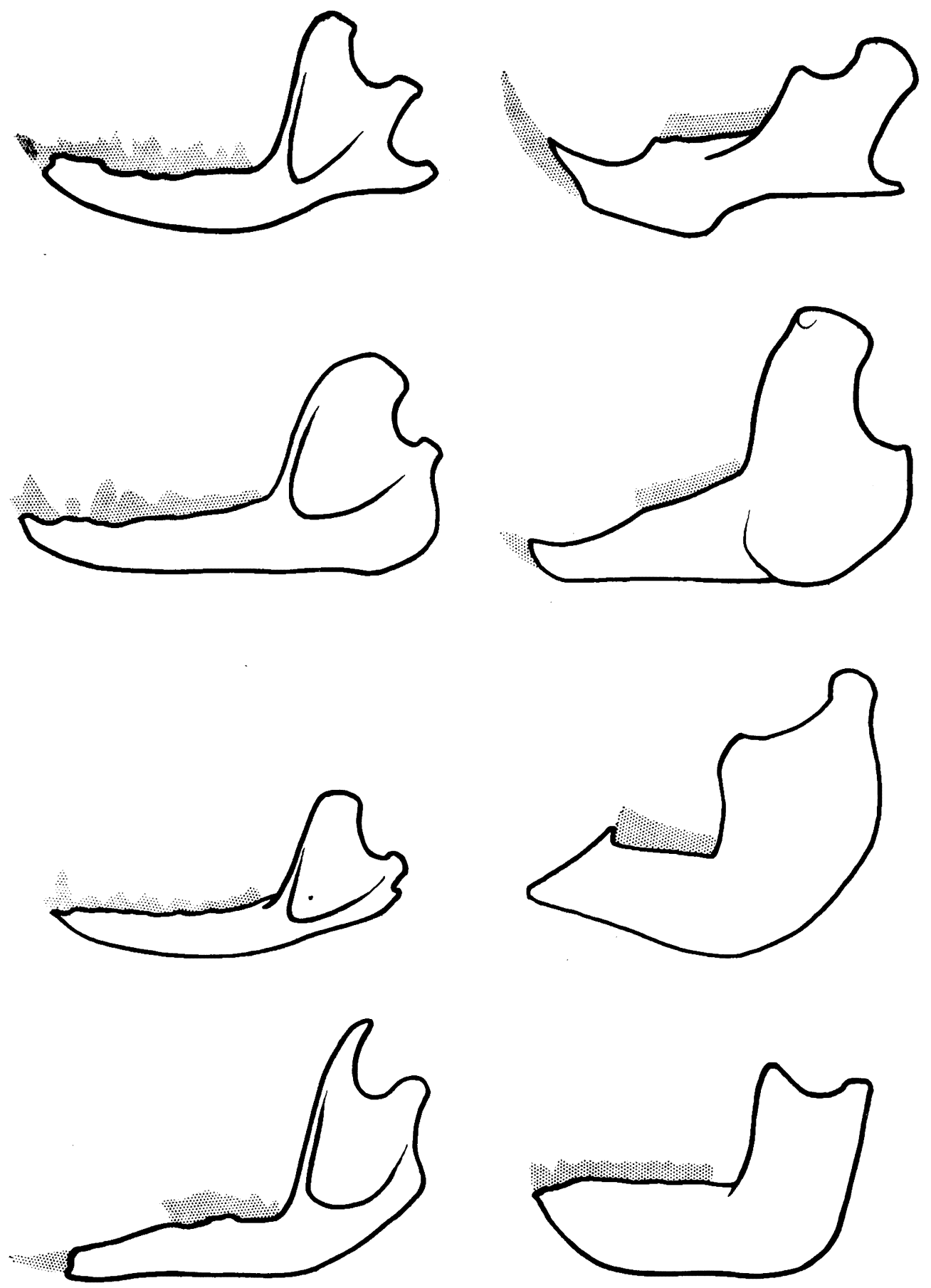

Fig. 3. Mammalian mandibles in Norma lateralis. Left: (top to bottom) hedgehog, Bonin flying fox, Australian native cat, great-grey kangaroo. Right: Canadian porcupine, Japanese hare, Indian elephant, Japanese macaque. 
It must be remembered that flying foxes are frugivorous in spite of dominance of the carnivorous character in their mandibles. The following inference may be drawn that the flying fox was once insectivorous but later changed its food habit into fruit-eating.

The Mandible of Rodentia and Lagomorpha (13 rodents, 2 hares). A peculiarly prolongated shape of the anterior part of the mandible is characteristic of these groups: it is due to their disproportionately large, curved incisors. In other points of view, however, the mandible of the groups bears some resemblances to that of ungulates. A depression which probably corresponds to the masseteric fossa is sometimes present though manifold in size and shape. The coronoid process shows a wide variation: it is well developed in Muridae (rats which eat small animals beside vegetables), medium in Sciuridae (squirrels which eat nuts, barks, etc.), poorly developed in Hystricidae (porcupines), or only vestigial in Caviidae (guinea pig, etc.) and Lagomorpha (hares), all the latter three eating berries, vegetables, grass, etc. The angular process is present in all rodents. It is a large bony plate in many species, markedly different in shape from that of carnivores. Since the masseter and the medial pterygoid muscles are attached to this process in both rodents and carnivores, the functional meaning seems to be the same among them, despite the difference in shape. In hares, on the contrary, the mandibular angle is rimmed by a rounded protuberance without process. Weber classified the rodents as the animal with a short condyloid process. But the condyle height index ${ }^{1)}$ in rodents ranged from 1.9 to 48.1 (mean 15.6). The rodents with small or vestigial coronoid process have short condyloid process, but others are varied in height. The variety covering the entire ranges of both carnivores and ungulates is characteristic of the rodents. In hares the index is 36.7 and 23.2.

It is concluded that the mandible of rodents and lagomorphs has some features in common with that of ungulates, but is clearly different from that of carnivores. But the shape of the mandibular body, angular process, and height of the condyloid process are different from those of the ungulates or of the carnivores.

The Mandible of Marsupialia (2 zoophagous, 5 phytophagous). The animal-eating marsupials feed themselves with earth-worms, small animals, etc. The shape of their mandibles is so similar to those of the carnivores that the former is hardly distinguished from the latter. Many characters such as the canoe shaped body, large

1) The criterion of the index was slightly modified in this group. The anterior point $\mathrm{A}$ in Fig. 1 was substituted by the anterior end of the utmost mesial molar, because the anterior portion of the mandible is transformed due to the specialized incisors. 
coronoid process, well-developed masseteric fossa, the presence of the angular process, etc. coincide with those of the carnivores. The condyle height index (12.9 and 17.4) is inside the range of carnivores.

The plant-eating marsupials, feeding themselves with flowers, leaves, and roots of plants, show considerably different features of the mandible from that of the animal-eating marsupials. The mandibular body resembles that of ruminants: gradually tapering toward the symphysis which holds horizontally projected incisors. The coronoid process is somewhat more massive than in the ruminants. The condyloid process is tall as in the ungulates (mean 22.1, ranging 18.3 to 27.7). The angular process is absent. There are, however, two points in which the marsupials differ from the ungulates: the lower part of the mandibular angle is bent medially at a right angle to make a large shelf-like protuberance; and there is a large and deep masseteric fossa on the lateral surface of the ramus. It is interesting that the forms belonging to the same taxonomic order have mandibles of different shape which may have been caused by the difference of their food habit.

The Mandible of Proboscidea (one Indian elephant). The mandible of the elephant is somewhat specialized. The body is short and massive. Each half carries one or two molars and the anterior end is pointed as if it were obliquely cut off. But other parts bear the characteristics of the ungulates' mandible: the condyloid process is considerably tall (index 64.2), the coronoid process is small, the mandibular angle is rounded without process. The lateral surface of the ramus is strongly elevated and there is nothing like the masseteric fossa.

The Mandible of Primates (2 platyrrhines, 6 catarrhines including anthropoids). As is commonly known, the omnivorousness (Polyphaga) is one of the characteristics of primates. In general, however, many features of the mandible coincide with those in ungulates: the shape of the coronoid process resembles that of the non-ruminants; there is no. trace of the angular process; the masseteric fossa is limited to the upper portion of the ramus and not so deep as in carnivores; the lateral surface of the ramus is flat as in ungulates. The condyloid process is tall: the condyle height index is 28.7 (19.8-39.2). However, this value may be partly due to the relatively short body which is characteristic of the primates. This shortness of the body is brought about in course of evolutionary changes, rather than by masticatory function. 


\section{Summary of Findings}

The findings described above are summarised in Table 1 . It is easily understood that animals studied can be divided into two groups : the first group includes Carnivora, Chiroptera, Insectivora, and Zoophaga of Marsupialia ; and the second group includes Ungulata, Rodentia, Lagomorpha, Primates, Proboscidea, and Phytophaga of Marsupialia.

The mandibles of the first group are possessed of the following characters: (1) canoe-shaped mandibular body, (2) large triangular coronoid process, (3) large well-developed masseteric fossa which spreads over entire surface of the ramus, (4) presence of the angular process on the mandibular angle, and (5) short condyloid process in relation to the occlusal plane. On the other hand, the characteristics of the second group consist in: (1) flat and rough-surfaced ramus, (2) the mandibular body tapering toward the symphyseal part, (3) small and shallow masseteric fossa limited to the upper portion of the ramus, (4) small, or slender coronoid process which is in some forms (ruminants) fairly long and strongly curved posteriorly, and (5) tall condyloid process in relation to the occlusal plane of the molars.

In regard to the food habit, the first group is animal-eating (carnivorous or insectivorous), except Megachiroptera (frugivorous), while the second group is plant-eating (herbivorous or frugivorous). The first group should be named generically "Zoophagous Group"

Table 1. Summarised List of Characters of Mammalian Mandibles. character, $O$ : herbivorous character, $S$ : specific to respective group.

\begin{tabular}{|c|c|c|c|c|c|c|}
\hline & Corps & $\begin{array}{l}\text { Processus } \\
\text { coronoideus }\end{array}$ & $\begin{array}{c}\text { Fossa } \\
\text { masseterica }\end{array}$ & $\begin{array}{l}\text { Processus } \\
\text { angularis }\end{array}$ & $\begin{array}{c}\text { condyle height } \\
\text { index } \\
\text { mean (min.- } \\
\text { max.) }\end{array}$ & $\begin{array}{l}\text { t } \\
\mathrm{N}\end{array}$ \\
\hline Carnivora & $\boldsymbol{\Delta}$ & $\Delta$ & $\boldsymbol{\Delta}$ & $\boldsymbol{\Delta}$ & $7.7(0.95-18.2)$ & 24 \\
\hline Chiroptera & $\boldsymbol{\Delta}$ & $\Delta$ & $\Delta$ & $\Delta$ & $12.2(7.8-16.2)$ & 4 \\
\hline $\begin{array}{l}\text { Zoophaza of } \\
\text { Marsupialia }\end{array}$ & $\boldsymbol{\Delta}$ & $\Delta$ & $\Delta$ & $\Delta$ & 15. 2(12.9-17.4) & 2 \\
\hline Insectivora & $\Delta$ & $\Delta$ & $\Delta$ & $\Delta$ & $24.2(19.4-30.6)$ & 5 \\
\hline Ungulata & 0 & 0 & 0 & 0 & $25.6(16.0-39.4)$ & 16 \\
\hline Rodentia & $S$ & 0 & 0 & $\Delta$ & $15.6(1.9-48.1)$ & 13 \\
\hline Lagomorpha & S & O & 0 & O & $30.0(23.2-36.7)$ & 2 \\
\hline $\begin{array}{c}\text { Phytophaga of } \\
\text { Marsupialia }\end{array}$ & O & 0 & 0 & $\mathrm{~s}$ & $22.1(18.3-27.7)$ & 5 \\
\hline Primates & S & 0 & 0 & 0 & 28. $7(19.8-39.2)$ & 8 \\
\hline Proboscidea & S & 0 & 0 & 0 & 64.2 & 1 \\
\hline
\end{tabular}


and the second "Phytophagous Group". Consequently it becomes clear that the mandible of animal-eating mammals is uniformly possessed of a set of particular characters, whereas in the mandible of plant-eating mammals, another set of characters is found beyond the taxonomic differences. It must be noted that variations are greater amony Phytophagous Group than among Zoophagous Group.

As far as the shape of the mandible is concerned, no special character common to omnivorous forms can be picked up. The mandibles of some omnivorous forms can be without dispute classified into Zoophagous Group (bear, racoon, coati, badger, racoon dog, fox, marten, etc.) and others into Phytophagous Group (non-ruminants, primates, and rats).

\section{Discussions}

The present observation has made it clear that the shape of the mandible, especially that of the ramus, is conditioned by the food habit beyond the differences in taxonomic possessions. Consequently the next problem arises: how the food habit acts on the shape of the mandible? Since every food habit may require particular masticatory function, this problem can be expressed as: why such and such structure is advantageous to such and such masticatory function? It is clear however, that the masticatory function depends largely on the structure of teeth and muscles of mastication and these exert a great influence on the structure of the mandible. To know detailed role of teeth and muscles in respective kind of mastication, further dissectional studies are necessary.

The length of the condyloid process, i.e. the height of the condyle, is subject to wide variation from species to species as observed. Generally speaking, the condyloid process of the phytophagous form is long and that of the zoophagous is short irrespective of their taxonomic position. The difference between rodents and hares is worth noticing in relation to the problem. The height of the condyloid process varies greatly among rodents, while it is always tall in the hares. In the former, the mandibular joint and the structure of the molar cusp allow the mandible to move only in sagittal direction, while it besides allows lateral movement, grinding, in case of the latter. Also in ungulates, primates, elephants, and plant-eating marsupials, the mandible can more or less move in all direction on the horizontal plane, and the condyloid process is tall. It suggets that there is some relationship between tallness of the condyloid process and the grinding movemont of the mandible: in other words, the tall condyloid process may be advantageous to the 
phytophagous type of mastication.

Basing on the fact that the process was very short in Cetacea, Monotremata, Manis, and Myrmecophaga, Weber suggested that the slow mastication might be related to the shortness of the condyloid process. But the opinion is not tenable in cases of the fissipede carnivores.

Peteff pointed out in his study of occlusal pressure that in case of the short condyloid process, i. $\theta$. the condyle being placed near the occlusal plane, the lower teeth almost vertically met the upper teeth at mastication. In other words, the axis of a tooth approximately coincides with the tangent of the rotation curve of the tooth around the condyle. Therefore the force of muscle is utterly exerted in the very direction of the tooth-axis. This is apparently advantageous for carnivores to thrust their pointed teeth into the prey. But he mentioned nothing about the tallness of the condyloid process in the ungulates' mandible.

Kühlhorn mentioned that the pattern of mastication among mammals was divided into two types: Grasp-type (Greif-Typ) as seen in carnivores, and Grind-type (Kau-Typ) as seen in ungulates. The grasp-type of mastication chiefly consists of up and down or hinge movement of the mandible and can be analysed into three roles: seizing, biting and splitting. In animals of this type, the temporalis muscle is considerably stronger than the masseter. Because of the shortness of the condyloid process, the distance between the condyle and the upper part of the coronoid process (=the attachment of the temporalis) is relatively long. Consequently the force of the temporalis is efficiently utilized according to the principles of the lever and fulcrum, and the seizing action is carried out assuredly.

In the grind-type of mastication, on the other hand, the chief action consists of pressing and crushing caused by the grinding movement of the mandible, and the seizing is rather of little importance. In animals of this type, the masseter is relatively welldeveloped and the temporalis is weak. Kühlhorn applies the similar way of explanation: in case of the tall condyloid process, the distance of the condyle from the mandibular angle (=the attachment of main parts of the masseter) is relatively large. Thus the masseter could lift up the mandible and press it to the maxilla with little difficulty in aid of the leverage.

It is easy to suppose that the tall condyloid process will be accompanied by the long masseter muscle. Schumacher measured the length of the masseter: $20.75 \mathrm{~mm}$ in roe deer, $20.7 \mathrm{~mm}$ in sheep, $30.05 \mathrm{~mm}$ in wolf, and $28.6 \mathrm{~mm}$ in lion. By rough calculation, the 
relative length of the masseter [ $100 \times$ masseter length (Schumacher)/ mandibular length (Hoshi)] is 13.1, 14.8, 19.3, and 13.4, while the condyle height index is 27.1, 27.4, 12.0 and 0.95 respectively. Schumacher measured the superficial portion of the masseter, fibers of which take an oblique course from antero-superior to posteroinferior, while the deep portion of the muscle is almost vertically inserted to the mandibular angle. Kühlhorn's explanation may be admitted as far as the deep portion of the masseter is concerned. As shown in Fig. 4, the vertical component of mastication force is greater in case of the tall condyloid process. This condition is advantageous to the grind-type mastication, in so far as the lower jaw is pressed up to the upper jaw with the least loss of mastication force. The pressing is necessary for the grinding to be effective.

When the mandible is moved upward to the maxilla, the corresponding teeth of upper and lower jaws meet with each other in an oblique direction to the tooth-axis in case of the tall condyloid process (e.g. in ungulates). In this case, the horizontal component of the mastication force is considerably great as seen in Fig. 5 . This horizontal force in the sagittal direction must contribute to the grind-type mastication which mainly consists of the grinding action in the transverse direction. On the contrary, the horizontal component is negligible in case of the short condyloid process (e.g. in carnivores), so that the mastication force is thrown entirely to thrust the pointed teeth into the prey as described by Peteff.
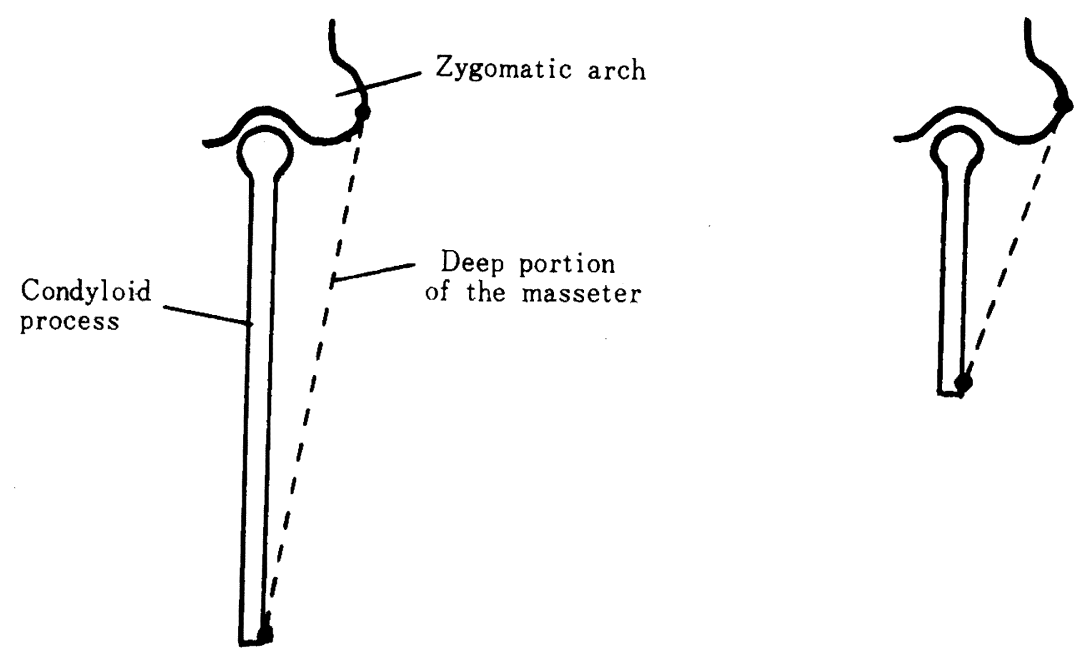

Fig. 4. Diagrams showing the difference in the relation of the masseter to the condyloid process by tall and short condyloid process. The force of the masseter is more efficiently utilized for vertical component (pressing) in case of the tall condyloid process (left) than in case of the short condyloid process (right). 


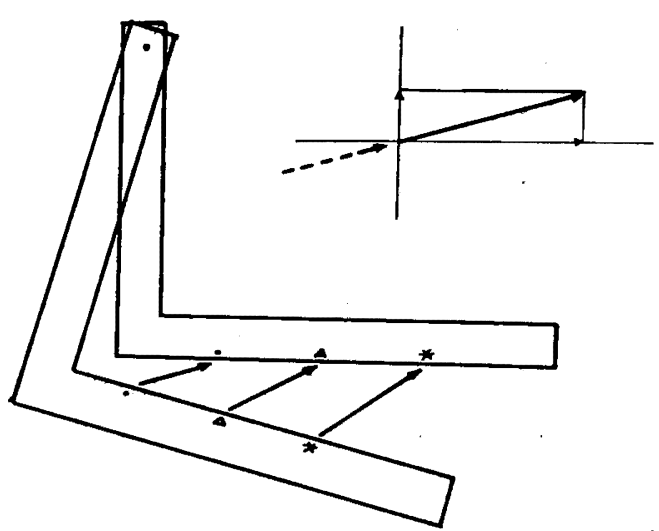

Tall Condyloid Process

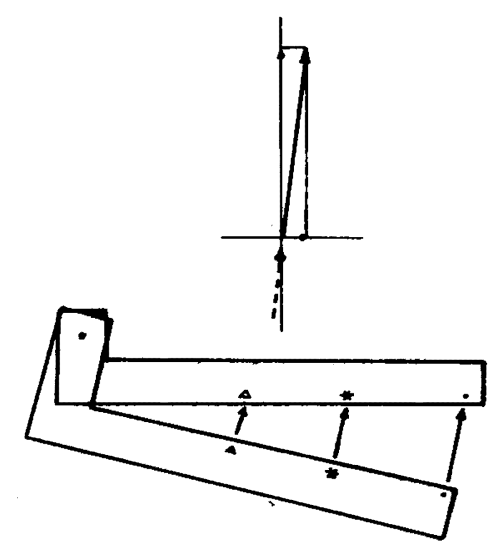

Short Condyloid Process

Fig. 5. Diagrams showing the difference in movement of the mandible by tall and short condyloid process in reference to the meeting direction of the corresponding teeth of the upper and lower jaws (see text).

\section{Summary}

The comparative study on the morphological characters of the mandible in Norma lateralis was made in 78 species of mammais. In the present investigation, special attention was paid of the relation of mandibular shape to food habit.

(1) All mammals can be divided into two groups according to the mandibular shape: the first group comprises Carnivora, Chiroptera, Insectivora, and Zoophaga of Marsupialia, and the second group, Ungulata, Rodentia, Lagomorpha, Primates, Proboscidea, and Phytophaga of Marsupialia.

(2) The characteristics of the first group consisted of large coronoid process, well-developed masseteric fossa, styloid angular process, short condyloid process, and canoe-shaped body, while the second group is characterised by small or slender coronoid process, small and shallow massecteric fossa, absence of the angular process (except rodents), tall condyloid process, and tapering body with slight modifications.

(3) In view of the food habit, the first group is animal-eating (except Megachiroptera), and the second, plant-eating. Therefore, the author calls the former "Zoophagous Group" and the latter "Phytophagous Group". It is suggested that Megachiroptera may have lately changed its alimentation from insectivorous to frugivorous style. 
(4) There is no specific character common to omnivorous animals. Those included in Carnivora have the mandible of zoophagous type, while those included in Ungulata and Primates have the mandible of phytophagous type.

(5) Functional significance of each character specific to the Zoophagous and Phytophagous Groups was discussed with special regards to the causal relationships between the mandibular shape and the food habit. It was clarified that the tallness of the condyloid process was advantageous to the phytophagous type of mastication (grinding) and the shortness of the condyloid process was most. favourable for the zoophagous type of mastication (seizing).

The author is greatly indebted to the late Dr. Tsunetaro Fujita, Professor. emeritus of Anatomy, University of Tokyo for his directions and suggestions. He also deeply appreciates many precious advices from Dr. Yoshinori Imaizumi, Director of Zoological Department, National Science Museum in Tokyo. Many thanks are expressed to Dr. Harumi Terada, Professor of Anatomy, Kitasato University, for his. kind help in preparing the manuscript.

\section{Literature}

Bechet, G. (1954). A comparative biological and anatomical investigation of the masticatory apparatus of some mammals. Ned. t. Geneesk., I, 98.

Bolk, et al. (1936). Handbuch der vergleichenden Anatomie der Wirbeltiere. Vol. IV, Urban u. Schwarzenberg.

Eisler, P. (1912). Die Muskeln des Stammes. Bardeleben's Handbuch der Anatomie des Menschen. II-2-(i): 197-220, Jena.

Grassé, P.-P. (1967). Traité de Zoologie. Tome XVI. Mammifères téguments et. squelett. Masson, Paris.

Gegenbaur, (1898). Vergleichende Anatomie der Wirbeltiere. Vol. I, Leipzig.

Häberle, E.L. (1950). Die Höhe des Proc. muscularis mandibulae bei Masseter- und Temporaliskauern. Med. Diss. Erlangen.

Kühlhorn, F. (1938). Anpassungserscheinungen am Kauapparat bei ernährungsbiologish verschiedenen Säugetieren. Zool. Anz., 121: 1-17,

Lebedinsky, N.G. (1938). Über die funktionelle Bedeutung der verschiedenen Höhe des Ramus ascendens mandibulae bzw. des Unterkiefergelenkes bei Säugetieren. Vjschr. naturfor. Ges. Zürich, $83: 217-224$.

Lubosch, (1907). Universelle, specialisierte Kaubewegung bei Säugetieren. Biolog. Centrbl., $27: 613-624,652-665$.

Martin, R. und Saller, K. (1957). Lehrbuch der Anthropologie. Vol. I, 3. Aufl., G. Fischer, Jena.

Peteff, D. (1927). Kaukraft und Kaudruck bei grossen und kleinen Tieren. Dtsch. Monschr. Zahnhk., 45-Jahrgang : 919-929.

Schumacher, G.H. (1961). Functionelle Morphologie der Kaumuskulatur. G. Fischer. Jena.

Toldt, C. $(1904,1905)$. Der Winkelfortsat $z$ des Unterkiefers beim Menschen und bei den Säugetieren und die Beziehungen der Kaumuskeln zu demselben. Sitz. Ber. Mathem. Naturw. Klasse d. Kais. Akad. Wiss. in Wien, Abt. III, 113, 114.

Weber, M. (1927). Die Säugetiere. Vol. I. Anat. Teil, G. Fischer, Jena.

Wiedersheim (1909). Vergleichende Anatomie der Wirbeltiere. G. Fischer, Jena. 